\title{
Toward a Start-to-Finish Cross-Disciplinary Instructional Model for National and International Higher Education
}

\author{
Victor William Harris ${ }^{1, *}$ \& Heidi Harris ${ }^{2}$ \\ ${ }^{1}$ Family, Youth and Community Sciences, University of Florida, Gainesville, Florida, USA \\ ${ }^{2}$ Instructional Design and Technology, Concordia University, Chicago, Illinois, USA \\ *Correspondence: Family, Youth and Community Sciences, 3028 D McCarty Hall D, University of Florida, \\ Gainesville, Florida, USA. Tel: 1-352-273-3523. E-mail: victorharris@ufl.edu
}

Received: February 20, 2020

Accepted: March 25, 2020 Online Published: April 20, 2020

doi:10.5430/wje.v10n2p141

URL: https://doi.org/10.5430/wje.v10n2p141

\begin{abstract}
Using their cross-disciplinary review of Ideas that Work in College Teaching, the authors explore the pedagogical commonalities of fifteen higher education instructors from SUNY Potsdam (State University of New York at Potsdam) in an attempt to reveal the secrets of teaching success across thirteen academic disciplines - math, computer science, geology, modern languages, political science, philosophy, history, biology, psychology, sociology, physics, and art. While the specific instructional disciplines varied considerably in the content that was both studied and presented, the authors found that the principles of effective teaching were quite similar across each of these disciplines. The insights shared by these fifteen accomplished instructors provide pedagogical wisdom that all teachers can learn from regardless of context or developmental age and stage of student capability and competence. Common goals and principles associated with effective teaching in higher education are highlighted using specific examples from individual authors where appropriate. A new model of instruction is then introduced: Attention, Interact, Apply, Invite - Fact, Think, Feel, Do (AIAI-FTFD), as a potential start-to-finish approach to effective teaching in higher education. Implications for use of the model in both national and international higher education contexts are discussed.
\end{abstract}

Keywords: effective teaching, higher education, pedagogy, instructional model, AIAI-FTFD

\section{Introduction}

The landscape of higher education is changing (Darling-Hammond 2006; Weimer 2013). While the traditional model of using stand-and-deliver teaching methodologies is still very much present and retains some value (Middendorf and Kalish 1996), this model is falling out of favor with many $21^{\text {st }}$ century learners and is seen as less effective at preparing students for real-world application in the workforce (Knight and Wood 2005). This finding is supported by previous studies (Fensham, 1992; Johnstone and Percival 1976), which found adult learners are capable of paying attention to lecture format delivery for only 15 to 20 minutes before losing focus mentally. In addition, as the lecture continues, a learner's attention span tends to decrease, often dropping to 10-18 minutes. This phenomenon highlights the need for more effective and interactive instruction.

To adapt to the needs of learners and respond to calls from business and industry for employees with translatable skills, educators are increasingly shifting from a teaching paradigm (i.e., teacher-centered) to a learning paradigm (i.e., learner-centered) (Guskin, 1994; Weimer, 2013). Part of shifting to a learning paradigm consists of shortening lecture times along with adding more time for interactions (e.g., teacher-learner, learner-learner, learner-content, and learner-technology interactions), including small group discussions, applicable stories, and buzz groups (Middendorf and Kalish 1996). More specifically, the learning paradigm promotes (a) learner-centered application of concepts and principles; (b) active learning through participation; (c) group and teamwork exercises; (d) critical thinking discussions; (e) problem-based and project-based cooperative and collaborative learning; and (f), other related activities, most of which are associated with experiencing real-world contexts or solving real-world problems.

\subsection{Review: Ideas That Work in College Teaching}

In this section, the authors introduce a cross-disciplinary review (Author 2009) of Ideas that Work in College 
Teaching (Badger 2008) to explore the pedagogical commonalities of fifteen instructors from SUNY Potsdam (State University of New York at Potsdam) in an attempt to reveal the secrets of teaching success across thirteen academic disciplines - math, computer science, geology, modern languages, political science, philosophy, history, biology, psychology, sociology, physics, and art. While the specific teaching disciplines varied considerably in the content that was both studied and presented, the authors found that the principles of effective teaching were quite similar across each of these disciplines.

\subsection{Goals of Effective Cross-Disciplinary Teaching}

The goals of effective teaching outlined below purposefully include many of the original words of the instructors to provide both insight and depth into the common threads that are interwoven throughout various academic disciplines. For example, William E. Herman, instructor of psychology, reminds us that most of us ". . . joined the academic ranks in order to maintain the momentum of intellectual stimulation nurtured in graduate school and to make a positive difference in the lives of students and society." He then states that the goals of teaching, as he perceives them, are to ". . . focus on the exploration, creation, advancement, maintenance, critical assessment, and reality testing of knowledge." This was reiterated by Joel Foisy, instructor of mathematics, who believes the overall goal of teaching is to help students "think for themselves" regardless of the academic subject. History instructor Ronald Woodbury shares this belief because "history is interpretation of the meaning and significance of the past, not the past itself . . .." and is ". . . best understood through an interactive process of testing and refining ideas." This is supported by Sergei Abramovich, instructor of teacher education, whose goal for mathematics education is to use technology, such as computers, to encourage interactive (i.e., "dialogic") communication between both student and subject.

The goal of "testing and refining ideas" is also shared by David Curry, instructor of philosophy, although the means he employs to help students reach this end is not commonly shared by all instructors. His goal is to "create, disseminate, share, and foment confusion" among his students so they are forced to rethink and even unlearn old patterns of thinking. Then he, as the instructor, models ways of "negotiating that confusion" by teaching his students what he calls "critical thinking in action" through the "give-and-take of reason and argument." It was Socrates' goal, Curry claims, to encourage the moral improvement of both himself and others, for, as Socrates stated in the Apology, "the unexamined life is not worth living." Thus, Curry's overriding teaching goal is to help his students to see ". . . that a worthwhile life requires that one be constantly checking up on one's beliefs, particularly one's moral beliefs, subjecting them to a kind of eternal recurrence of cross-examination."

Oscar Sarmiento, instructor of modern languages, echoes Curry's sentiments with a similar goal for student learning outcomes, ". . . when students learn something valuable, something that is truly relevant, it radically affects their perceptions and values." When this occurs, instructor of sociology Heather Sullivan-Catlin believes that the sense of hopelessness that many students feel about their powerlessness to effect change in the world is replaced by a sense of efficacy and a belief that they can enact real change that really matters.

\subsection{Principles of Effective Cross-Disciplinary Teaching}

For Sullivan-Catlin, the teaching goal of replacing hopelessness with efficacy can best be reached by engaging her students in community work through service learning and a principle she calls "resocialization" (i.e., "the process of socializing people into new cultures and environments, like a new job"). She believes that it is the teacher's responsibility to help students make the connection between what she calls the "theoretical" and the "experiential." When students are actively engaged in solving real-world problems, they begin to believe that they can make a difference. Examples of community service assignments she uses to engage students include tutoring, conducting needs assessments, public awareness through the creation of media and marketing materials, and presenting diversity workshops.

Joel Foisy, instructor of mathematics, also believes student engagement is the key to effective teaching. He focuses on specific practices in the classroom that foster participation, such as using a variety of methods, keeping teaching standards high but not so high that students "panic" or "feel demeaned," and balancing lecture with projects and activities that will allow the students to work together and gain real-world experience. He stresses the importance of what he calls "quick activities," such as using jokes and other kinesthetic activities (e.g., having the students stand and create angles with their arms) to catch the students' attention and keep them engaged in the learning process. He is also a proponent of reflective questioning in which he will reflect student questions directed to him back to the class in order to generate increased discussion.

Peter Brouwer, instructor of computer science, uses projects, such as designing multiprogramming operating systems, 
to help students learn real-world skills, such as problem solving, teamwork, interpersonal skills, creativity, and project management. Project grades are given to the entire group, although the use of peer evaluations allows for the grade to be adjusted up or down based upon individual contributions to the project.

Caroline Downing, instructor of art, uses a balance of lecture about art history, studio art assignments, and "field trip Fridays" to engage her students in the principles of perspective, balance, and color harmony. She states, "Many [of her students] are surprised to learn that perspective, for example, is not a universal scientific 'given,' but a cultural creation ...."

Robert Badger, instructor of geology, believes he can help his students teach an "old rock new tricks" by having them engage in third person writing about the events of their class geological field trips to someone who is not knowledgeable about the subject. Such a process, Badger articulates, increases student descriptive writing skills and solidifies their understanding of what they have both seen and learned.

Lawrence Brehm, instructor of physics, emphasizes that the instructor has little control over the "state of mind" the student enters the classroom with but that it is his desire, as an instructor, to help his students become curious about how things work and why. He admits that one of the biggest challenges of teaching is that students have to "unlearn" so much of what they previously thought was correct so they can "learn" about how things actually work. He has moved away from much of the traditional lecture to inquiry- and discovery-based learning. He concedes that much of this type of learning takes place in a laboratory setting where students can "grapple" with certain tasks. This setting also allows him to consult with his students individually based upon their specific needs and questions. He also offers office visit coupons to his students that can only be redeemed within a certain number of days so he can meet with them individually about the homework questions they have. He believes that the successful navigation of the homework problems is critical to student learning and success.

Ronald Woodbury, instructor of history, has also replaced much of the lecture focus in his classes with debates, films, oral presentations, and small group discussions. For him, writing is a primary component of critical thinking, and he is careful to structure his writing assignments to help his students learn about what good writing is and how it can be achieved.

Peg Wesselink, instructor of politics, uses poster cards to help students identify important women and timelines in political thought while Walter Conley, instructor of biology, uses activities such as plays to teach the process of photosynthesis. Students dress up and play the parts of water, sunlight, carbon, and the electron transport chain in order to better understand this life-giving process.

\subsection{Synthesis and Insights}

A synthesis of the goals and principles of effective teaching shared by the instructors at SUNY Potsdam suggests that assessing who our students are and what they really need while trying to balance these needs with instructor needs and curriculum demands creates a unique context for establishing "points of engagement" between student, instructor, and subject. The primary rationale articulated by these instructors appears to be that shared by Walter Conley, instructor of biology, who has found that interest in a topic creates motivation to learn and that it is a teacher's responsibility to use whatever creative teaching methodologies are available to spark that interest and create ever increasing points of engagement between the student, instructor, and the subject.

Oscar Sarmiento, instructor of modern languages, emphasizes how "precious" these points of engagement are for creating effective learning outcomes. "I surely wish," he said, "we could find a magical formula to keep a class session from losing its precious intensity and edge." This "intensity" and "edge" is created or lost due to how well the instructor facilitates these connections. It appears, then, that successful and effective teaching can be evaluated by both the quality and the quantity of the points of engagement the instructor is able to facilitate and by how well these engagement points are able to be maintained throughout a classroom experience.

Several points of engagement these instructors have in common include the desire to help their students think differently, to view topics from different vantage points, and thereby to increase awareness and ability to think critically. In other words, as Joel Foisy highlights, they want their students to learn to "think for themselves."

Bloom's taxonomy exposes the problem associated with so much of ineffective teaching, which is that many instructors "teach facts to the test" and focus primarily on "remember" and "understand" as the two major mental processes of learning. When students are only required to remember facts and understand concepts without application to their own experience, few points of engagement are created. When student interest is sparked and they are challenged and motivated to use not only the mental processes of remember and understand, but to analyze, solve, and create while making application to their own real-world experiences, it opens up a "thousand points of light." It 
is in this light that the teaching experience becomes magical. On the other hand, when we do things that cause students to disengage, to feel bored, to panic, to feel lost, or to feel demeaned in any way, we can engender, as Lawrence Brehm, instructor of physics, insightfully shares, "a truly robust hatred" for the subject.

\subsection{Who Are the Students Really?}

David Curry, instructor of philosophy, shares a personal assessment of the typical student who enters our classroom that is both insightful and entertaining:

"Consider our students: They are, in short, a mass of latent contradiction and tensions: a fertile field of potential confusion ready for the harvest. They have absorbed the ubiquitous moral Puritanism of our society along with the equally ubiquitous commercialization of sex and violence. They live in the most widely touted democracy in the world, in which oligarchs and corporations compete for leadership and set the social and political agenda. They live in the largest secular and multicultural society in the world, yet retain a puritanical provincialism and a naive spiritualism. They are raised in a world made by science, yet place their hopes in psychic hotlines and the power of crystals to heal. They are individualists who just happen to all wear the same brand of jeans. They are moral relativists who are proud to proclaim their allegiance to the universal moral truth du jour. They are already a bundle of confusions and contradictions, though they are also, amazingly, completely unaware of the fact. They take it for granted that they are savvy, skeptical, clever, and informed when their entire educational history up to the day they enter our classrooms has almost certainly been little more than teaching facts to the tests, and has certainly not required subtlety of thought, has discouraged any sort of mitigated skepticism, has impeded cleverness, and has, at best, kept them minimally informed by convincing them to take mainstream commercial media as their sole source of information. Equally amazing is the fact that some of them have actually survived this process, or at least are salvageable." (p.71)

Carol Downing, instructor of art, identifies two primary challenges to teacher effectiveness with their students: 1) students' "short attention spans;" 2) students" "profoundly visual orientation to learning." She states,

"Most of today's students have, after all, spent many more hours watching television, playing video games, or surfing the net than they have reading books. They have developed as part of a visual culture unimagined when many of their professors went to school. That visual culture contributes to the formation of limited attention spans because its manifestations (think of MTV), feature fast-moving, brightly colored, and rapidly changing segments. The typical college lecture course, in comparison, cannot help but seem bland, colorless, and dull.” (p.51)

\subsection{What Do Students Really Need?}

A synthesis of information provided by the SUNY Potsdam instructors suggests that what they think their students really need is to learn to think, to question, to reason, to evaluate, to solve, to create, and to apply the topic being studied to their own real-world experiences. In sum, it is change that all of the instructors are seeking - change that informs, motivates, and inspires students to get involved and make a difference in their world; change that promotes self-efficacy and not helplessness; change that translates from cognition to real-world behavior.

\subsection{Active, Engaged Learning}

The principle of active learning is the teaching thread that weaves all of these instructors' teaching approaches together, regardless of topic or academic discipline. For example, Peter Brouwer, instructor of computer science, states simply that students must "do to learn." Caroline Downing, instructor of art studio and history, adds that students must be actively involved in the creation process. "Moving from passive listening to active practice," she articulates, "helps alleviate the problem of the short attention span." Similarly, Lawrence Brehm, instructor of physics, states that it is the teacher's role to create situations "to get the student to grapple with the topic, rather than listen to the teacher talk about it." To this end, Peg Wesselink, instructor of politics, argues "that varying information delivery and experiential learning, if done well motivates students to do the reading (and writing). ..." that are critical to success and that "finding activities that stimulate thinking about readings is a challenge" because "the activity needs to be creative enough to be playful, but not so creative that it is superficial."

\subsection{Summary Conclusion}

Teaching effectively is an art form. It is a dramatic production complete with actors, scripts, antagonists, protagonists, major dramatic questions, and the climax that resolves and answers all of these questions. It requires real intelligence - social, emotional, physical, intellectual, and, sometimes, even spiritual - to succeed. And it doesn't happen automatically, although I am convinced that almost anyone can learn to become a good teacher if they are willing to pay and enjoy the price to rise above the mediocrity that so often exists in the teaching world. We know from both 
research and observation that effective teachers, as evidenced by the instructors at SUNY Potsdam, are all as different in their personality types and teaching styles as the snowflakes that fall from the sky, but we have also learned that effective teachers share some common skills and some common teaching paradigms. Effective teachers care about their students; they are aware of their students' lives outside of the classroom; they are very socially, emotionally, and intellectually skilled; they listen; they discuss; they validate; they promote interaction; they ask good questions; they apply what they are teaching to their students' lives; they teach with clarity; they are knowledgeable and skilled at preparation and delivery of their discipline-specific teaching content; they provide a secure environment that invites their students to reflect, think for themselves, change, and gain new skills within the context of active learning.

\section{The AIAI-FTFD Start-To-Finish Instructional Model}

In an effort to teach strategically and effectively, the Attention, Interact, Apply, and Invite - Fact, Think, Feel, Do (AIAI-FTFD) Start-to-Finish Teaching Model (Figure 1) represents a theoretical and practical experiential approach to instruction (Author et al. 2014). The AIAI-FTFD model is supported by more than thirty years of teaching, teacher training, and observation. The model also has support from research in primary, secondary, community, and higher education contexts, involving all types of learners, including exceptional learners on both ends of the spectrum.

The full AIAI-FTFD model includes four distinct stages (1) Preparation, (2) Delivery, 3) Homework, and (4) Evaluation. The model can be used for designing, delivering, and evaluating full educational programs or individual instructional presentations and workshops. The Preparation Stage (Figure 1) includes (a) identifying the target audience; assessing the learners' felt, ascribed, and future needs (Powell and Cassidy 2007); (b) determining the top 2-3 concepts or principles to be used for teaching "less" better; (c) identifying cognitive, emotional, and behavioral target skills; (d) operationalizing these target skills into corresponding objectives, including establishing an overall goal for the presentation or program; (e) choosing which role the instructor will play (i.e., expert, facilitator, or consultant); (f) defining exactly what the instructor and the learner will do, and then (g) identifying what type of content, mental processes, and methods will be promoted in the educational session or program.

Similar to Merrill's (2002) four-phase model of instruction, the instructor facilitates the presentation by employing four steps or phases that promote best practices in teacher instruction and learning during the AIAI-FTFD model's Delivery Stage (Figure 1). The first phase, Attention, is designed to engage learners by focusing their attention on the task at hand through a short video, story, object lesson, or other learning activity. During this phase, approximately three-to-five minutes is the optimal time for instructors to engage learners and then guide them quickly to the next phase, Interaction. During this phase, the instructor engages learners by introducing relevant principles and concepts through different pedagogical and technological practices and programs. The goal of this phase is to promote developmentally appropriate comprehension and critical thinking among learners. The Application phase follows, wherein learners are encouraged to make practical, real-world applications of principles covered. Typically, a 5-10-minute practice activity is introduced so learners can practice and gain confidence using the principles, concepts, and skills learned. Invitation, the final phase, encourages learners to take the skills they learned and commit to practicing them outside the classroom (Author et al. 2014). Assigning homework, learning labs, and other activities designed to solidify knowledge and skills learned during the instructional session represent some best practices and programs that often accompany this phase.

The Homework Stage includes designing homework, assignments, labs, and other out of class practice activities that specifically address the identified instructor-targeted cognitive, emotional, and behavioral skills. These skills are operationalized and mapped to the cognitive, emotional, and behavioral learning objectives and outcomes. Targeted learning outcomes are carefully assessed in the Evaluation Stage, in which a specific instrument is designed to assesses the identified cognitive, emotional, and behavioral learning outcomes. What is unique about the AIAI-FTFD model, when compared to the instructional design models reviewed by Merrill (2002), is that it specifically divides the learning process into these four distinct stages while most instructional design models focus only on the Delivery Stage. Additionally, while these instructional designers focus on general instructional practices, the AIAI-FTFD model offers a specific start-to-finish approach to teaching and learning that beginning, intermediate, and advanced instructors can easily adapt and incorporate into their teaching paradigms. 


\begin{tabular}{|c|c|c|c|c|c|c|}
\hline $\begin{array}{l}\text { Preparation } S \\
\text { Target Audie } \\
\text { Learner Need } \\
\text { Content 2-3 C } \\
\text { 1. } \\
\text { 2. } \\
\text { 3. }\end{array}$ & $\begin{array}{l}\text { e: } \\
: \\
\text { cepts/Principles I wil }\end{array}$ & teach: & Ove & all Goal: & & \\
\hline \multicolumn{2}{|c|}{$\begin{array}{l}\text { 1. Cognitive/Know (C) - } \\
\text { 2. Emotional/Apply (E) - } \\
\text { 3. Behavioral/Practice (B) - }\end{array}$} & & \multicolumn{4}{|c|}{$\begin{array}{l}\text { Objectives (mapped to target skills): } \\
\text { 1. (C) - Participants will identify (know) ... } \\
\text { 2. (E) - Participants will apply ... } \\
\text { 3. (B) - Participants will practice ... }\end{array}$} \\
\hline \multicolumn{7}{|c|}{$\begin{array}{l}\text { AIAI-FTFD Variety: } \\
\text { Role: Expert, Facilitator, or Consultant (Circle One) }\end{array}$} \\
\hline$\underline{\text { Unit/Section }}$ & $\begin{array}{l}\text { Instructor Will Do } \\
\text { (List Items) } \\
\text { 1. (C) Know } \\
\text { 2. (E) Apply } \\
\text { 3. (B) Practice }\end{array}$ & $\begin{array}{l}\text { Learner Will } \\
\text { (List Items } \\
\text { 1. (C) Know } \\
\text { 2. (E) Apply } \\
\text { 3. (B) Practic }\end{array}$ & & \begin{tabular}{l}
\multicolumn{1}{c}{ Content } \\
(Circle Items) \\
This lesson \\
will use: \\
1. Facts \\
2. Concepts \\
3. Principles
\end{tabular} & $\begin{array}{l}\quad \underline{\text { Mental }} \\
\quad \underline{\text { Processes }} \\
\text { (Circle Items) } \\
\text { This lesson will } \\
\text { engage: } \\
\text { 1. Remember } \\
\text { 2.Understand } \\
\text { 3. Apply } \\
\text { 4. Analyze } \\
\text { 5. Evaluate } \\
\text { 6. Solve } \\
\text { 7. Create } \\
\text { 8. Design }\end{array}$ & $\begin{array}{l}\text { Method } \\
\text { (Circle } \\
\text { Items) } \\
\text { This lesson } \\
\text { will use: } \\
\text { 1. Audio } \\
\text { 2. Visual } \\
\text { 3. Praxis }\end{array}$ \\
\hline \multicolumn{4}{|c|}{ Delivery Stage: Lesson Outline } & Role: ExpeI & , Facilitator, Consu & $\tan t$ \\
\hline Attention: & & & & nteraction: & $\begin{array}{l}\text { ion Types: } \\
\text {-Fact } \\
\text {-Think } \\
\text {-Feel } \\
\text {-Do }\end{array}$ & \\
\hline $\begin{array}{l}\text { Apply: } \\
\text { Practice Targ } \\
\text { Invite: }\end{array}$ & kills: Cognitive, Emo & ional, Behavior & $l(5$ & minutes) & & \\
\hline
\end{tabular}

Figure 1. AIAI-FTFD Start-to-Finish Conceptual Instructional Model @ Victor Harris, VSI, Inc. 
The FTFD part of the AIAI-FTFD model is supported by best-practice instructional models as a method of effective questioning for learners. It uses the technique of asking Fact questions, or facilitating questioning that is factual in nature to assess previous knowledge (Example: What do you already know about this topic?), similar to Merrill's Principle 2. The questioning then moves to Thinking, focusing on asking questions geared to helping learners conceptualize and reason through the information presented (Example: What are some possible connections between these two concepts?), similar to Merrill's Principle 3. Following this step is Feeling questions, which are used to assess how learners can enact personal change from what they are learning (Example: How can you apply what you have learned today to your own context?), similar to Merrill's Principle 4. Lastly, there is the question type of Doing, inviting learners to enact lasting change in their lives by committing to use the knowledge and skills learned (Example: What will you do now to incorporate or internalize this concept/principle into your skill sets?), similar to Merrill's Principle 5 (Author et al. 2014). Specific program training and homework activities designed to help learners practice skills they have learned often accompanies these "Doing" types of questions.

In sum, the AIAI-FTFD teaching model was developed as a thorough, conceptual and principle-based, step-by-step, start-to-finish instructional model designed specifically to promote effective teaching and programming. Core principles represented in the AIAI-FTFD model include development of critical thinking skills, facilitation of group process and discussion, engagement of learners, and deployment of practice and program activities that facilitate acquisition of the identified cognitive, emotional, and behavioral target skills or learning outcomes. This model has been assessed in a variety of learning environments (Author et al., 2016).

\section{Implications of the AIAI-FTFD Model for National Higher Education}

Implications for use of the AIAI-FTFD Instructional Model in higher education in the United States are discussed below.

\subsection{Pedagogically Sound Instructional Model}

The AIAI-FTFD instructional model incorporates and expands on the best pedagogical practices of the last thirty years of instructional designers and learning theorists (Kurt 2015; Merrill 2002; Pritchard 2009; Reigeluth 1999; Reiser and Dempsey 2012). Principle-based instructional design represents the general format of most instructional design models. The AIAI-FTFD instructional model is a start-to-finish model that provides a step-by-step pattern for preparation, delivery, homework, and evaluation (Author et al. 2014).

\subsection{Promotion of Active, Engaged Learning}

The AIAI-FTFD instructional model facilitates experiential learning and real-world problem-solving. With an emphasis on facilitation, the AIAI-FTFD model combines practical application of the content with a specific focus on practicing cognitive, emotional, and behavioral target skills and assessing resultant learning outcomes.

\subsection{Cross-Disciplinary Utility}

The AIAI-FTFD instructional model is an effective tool in assisting instructors to prepare and deliver information regardless of disciplinary content. The review of Ideas that Work in College Teaching above highlights concepts and practices found within the AIAI-FTFD instructional model that give start-to-finish step-by-step specificity to teaching any topic, to any audience, within any context.

\subsection{Flexibility across Age and Stage of Developmental Learners}

The AIAI-FTFD instructional model is easy-to-learn and can be used among all types of learners, including young children, youth, adults, and those with disabilities. The step-by-step logical approach to learning found within the AIAI-FTFD instructional model allows instructors to deploy the model in 10-15-minute segments, as needed, to reach any developmental learning style or attention span.

\subsection{Promotion of Critical Thinking and Decision-Making}

The AIAI-FTFD instructional model allows instructors to specifically target cognitive, emotional, and behavioral learning skills that promote a wide range of engagement while scaffolding mental processes to make best practice decisions for meeting the unique demands of the tasks at hand. Cited as a potential intelligence (Gardner 1999), pedagogical intelligence requires critical thinking competencies in the preparation, delivery, homework, and evaluation stages of the AIAI-FTFD instructional model (Paul \& Elder 2019). 


\section{Implications of the AIAI-FTFD Model for International Education}

Implications for use of the AIAI-FTFD Instructional Model in international higher education subsume those listed for national higher education. Additional implications are discussed below.

\subsection{Contextual Reliability and Validity}

The AIAI-FTFD instructional model has been shown to be effective across a variety of learning and programming contexts (Author et al. 2016; 2018; 2019) and is in line with best practices in both national and international contexts (Hannover 2015; Merrill 2002; Reigeluth 1999; Reiser and Dempsey 2012). Experimental design is a logical next step to assess greater reliability and validity of the AIAI-FTFD model across contexts.

\subsection{Crosscultural Utility}

The AIAI-FTFD instructional model allows the instructor to be sensitive to individualistic and collectivist learning styles while creating a safe, anti-bias learning environment. It is designed to help learners feel culturally safe in any context while building cultural competencies and global awareness (Author et al. 2018).

\subsection{International Utility}

The AIAI-FTFD instructional model incorporates best practices for teaching a wide variety of international students (McFadden 2014) and best practices in global education that can be adapted to any specific instructional or learning need (Hannover Research 2015). The model is a tool that can be used for the instructional facilitation of experiential learning, positive attitudes toward diversity, deeper learning, and solving real-world problems in an interconnected global society.

\section{Conclusion}

With ever-expanding global awareness, technologies, and cross-national and crosscultural communications and collaborations, intentionally deploying an instructional methodology that can engage all types of learners regardless of context or developmental age and stage is critical to ongoing instructional effectiveness. The AIAI-FTFD start-to-finish instructional model represents one promising $21^{\text {st }}$ century methodology designed to help meet this growing need.

\section{References}

Badger, R. L. (2008). (Ed.). Ideas that work in college teaching. Albany, NY: State University of New York Press.

Darling-Hammond, L. D. (2006). Constructing $21^{\text {st }}$ century teacher education. Journal of Teacher Education, 57(3), 300-314. http://10.1177/0022487105285962

Fensham, P. J. (1992). Science education at first degree level. International Journal of Science Education, 14(5), 505-514. http://dx.doi.org/10.1080/0950069920140503

Gardner, H. (1999). Multiple approaches to understanding. In C.M. Reigeluth (Ed.), Instructional design theories and models: A new paradigm of instructional theory (Vol. II) (pp. 69-89). Mahwah, NJ: Lawrence Erlbaum Associates.

Guskin, A. E. (1994). Reducing student costs and enhancing student learning part II: Restructuring the role of faculty. Change, 26(5), 16-25. http://dx.doi.org/10.1080/00091383.1994.10544646

Hannover Research. (2015). Best practices in global education. Arlington, VA: Hannover Research.

Harris, V. W. (2009). Badger, R. L. (Ed.). Ideas that work in college teaching. Invited book review. Family Science Review, 14(2), 61-66.

Harris, V. W., Moen, D., Morrow, T., Teemant, B., \& Kumaran, M. (2014). Assessing the effectiveness of a Start-to-Finish Instructional Model in preparing human services and extension educators. Family Science Review, 19(1), 76-104.

Harris, V. W., Kumaran, M., Harris, H., Moen, D., \& Visconti, B. (2018). Assessing multicultural competence (knowledge and awareness) in study abroad experiences. Compare: A Journal of Comparative and International Education, 0, 1-23. https://doi.org/10.1080/03057925.2017.1421901

Harris, V. W., Sewell, C. B., Anderson, J., \& Speegle, K. C. (2019). Before you tie the knot: Mapping pedagogy, learning outcomes, and effect size in premarital education. Journal of Human Sciences and Extension, 7(3), 115-141. 
Harris, V. W., Speegle, K., Moen, D., \& Brooker, H. (2018). Teaching "less" better in higher education: A case study for exploring target skills and learning outcomes. Journal of Family Science Review, 22(3), 14-40.

Harris, V. W., Speegle, K., \& Schmeer, A. (2016). Teaching as an intervention: Evaluating 9 skills of communication in an extension learning environment. Journal of Human Sciences and Extension, 4(1), 139-158.

Johnstone, A. H., \& Percival, F. (1976). Attention breaks in lectures. Education in Chemistry, 13, 49-50.

Jonassen, D. (1999). Designing constructivist learning environments. In C. M. Reigeluth (Ed.), Instructional design theories and models: A new paradigm of instructional theory (Vol. II) (pp. 215-239). Mahwah, NJ: Lawrence Erlbaum Associates.

Knight, J. K., \& Wood, W. B. (2005). Teaching more by lecturing less. Cell Biology Education, 4, 298-310. https://doi.org/10.1187/05-06-0082

Kurt, S. (2015). Instructional design models and theories. Retrieved 9 December, 2015 from https://educationaltechnology.net/instructional-design-models-and-theories/

McFadden, C. (2014). Best practices for teaching international students. Journal of Modern Education Review, 4(10), 737-741. https://doi.org/10.15341/jmer(21557993)/10.04.2014/001

Merrill, M. D. (2002). First principles in instruction. Retrieved from https://www.indiana.edu/ tedfrick/aect2002/firstprinciplesbymerrill.pdf

Middendorf, J., \& Kalish, A. (1996). The change-up in lectures. The National Teaching and Learning Forum, 5(2), 1-5. https://doi.org/10.1002/ntlf.10026

Paul, R., \& Elder, L. (2019). The miniature guide to critical thinking. Dillon Beach, CA: Foundation for Critical Thinking Press. Retrieved from www.criticalthinking.org

Powell, L. H., \& Cassidy, D. (2007). Family life education: Working with families across the life span. Long Grove, IL: Waveland Press.

Pritchard, A. (2009). Ways of Learning: Learning theories and learning styles in the classroom (2nd ed.). New York: Routledge.

Reigeluth, C. M. (1999). (Ed.). Instructional design theories and models: A new paradigm of instructional theory (Vol. II). Mahwah, NJ: Lawrence Erlbaum Associates.

Reiser, R. A., \& Dempsey, J. V. (Eds.). (2012). Trends and issues in instructional design and technology (3rd ed.). New York, NY: Pearson.

Reiser, R. A., \& Weimer, M. (2013). Learner-centered teaching: Five key changes to practice (2nd ed.). San Francisco: Wiley and Sons. 